\title{
The influence of the luminance level upon the functional visual field for detecting a colored target
}

\author{
Mitsuo IKEDA*, H. UCHIKAWA** and M. AYAMA*
}

\begin{abstract}
The functional visual field for detecting a colored target out of colored background was determined for various luminance levels covering a range of $0.15 \mathrm{~cd} / \mathrm{m}^{2}$ through $30 \mathrm{~cd} / \mathrm{m}^{2}$. The background was consisted of two different colors distributed randomly over the field, each color element having a size of $2^{\circ} \times 2^{\circ}$ arc of visual angle. The visual field had a normal size of about $20^{\circ}$ diameter when transformed into an equivalent circular from with a high luminance level, but it contracted down to $8^{\circ}$ with the lowest luminance level employed. The importance to keep the luminance level above about $1.5 \mathrm{~cd} / \mathrm{m}^{2}$ was shown in order to avoid an extreme contraction of the functional visual field size under the experimental conditions investigated.
\end{abstract}

\section{Introduction}

The visual field size capable of detecting a target is greatly influenced by the background noise ${ }^{1)-4}$ ) and by the subject's mood toward the detection $\operatorname{task}^{5}$. In view of our daily experience to detect targets peripherally out of miscellaneous backgrounds, such as to detect traffic signals for example, it is very important to establish the functional visual field sizes quantitatively for various targetbackground combinations as well as for the illuminating conditions.

The present report particularly aims to investigate the influence of the luminance level upon the functional visual field when certain color chips are used as the target and the background field.

\section{Principle of experiment}

The test stimulus covered a wide field of $30^{\circ}$ arc of visual angle in height and $40^{\circ}$ in width. It was sectioned into $15 \times 20$ elements, each having a size of $2^{\circ} \times 2^{\circ}$ and one of two colors, red or green. These colors are denoted as $\mathrm{N}_{1}$ and $\mathrm{N}_{2}$, respectively. The two colored elements were distributed over the field in a randomized order with a certain ratio of number of two colors such as $\mathrm{N}_{1}-75 \%$ and $\mathrm{N}_{2}-25 \%$.

* Department of Information Processing Tokyo Institute of Technology Graduate School Nagatsuta, Midori-ku, Yokohama 227, Japan.

** Now at York University, Department of Psychology, Canada.
One of the background elements was replaced by another color, yellow, and it served as the target to be detected by the subject. He was presented with the test stimulus for a duration $100 \mathrm{msec}$ and asked to detect the target while fixating his eye at the center of the test stimulus field. By presenting the target at various locations, the functional visual field should be determined.

\section{Apparatus and procedure}

The apparatus to achieve the experiment was a two channels tachistoscope, one for the test stimulus field ST and the other for the pre- and post-adapting field $\mathrm{AF}$ as shown in Fig. 1. The subject $\mathrm{SU}$ sat

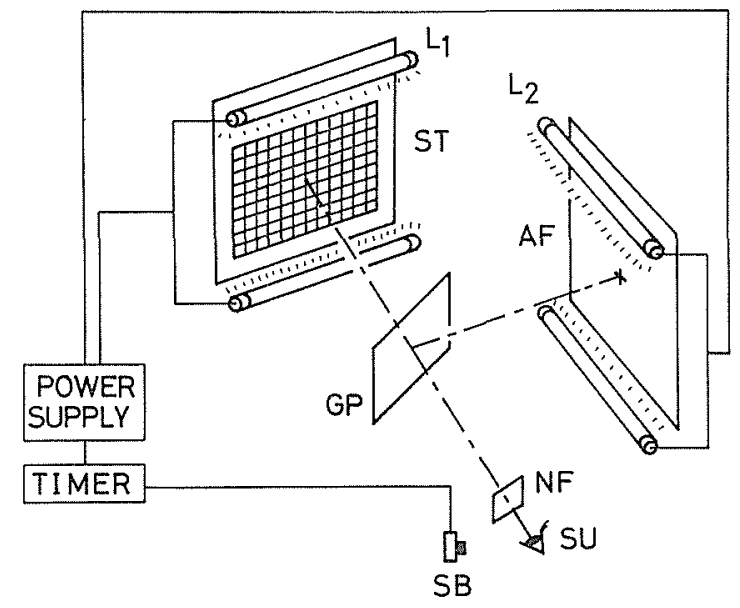

Fig. 1 Scheme of apparatus. 
with a chin rest at a distance $75 \mathrm{~cm}$ apart from both fields. He first observed monocularly with his right eye the uniform white adapting field $A F$ via a glass plate GP fixating upon a cross which situated at the center of the field. When pressed a starting button SB, the test stimulus field substituted the adapting field for $100 \mathrm{msec}$ and the adapting field was again presented afterward. These alternations were all conducted by fluorescent lamps $L_{1}$ and $L_{2}$ controlled by a timer and a power supply. The corelated color temperature of the lamps was about $5100 \mathrm{~K}$. The duration $100 \mathrm{msec}$ was chosen to exclude the eye saccades that might occur with longer periods than about $200 \mathrm{msec}$.

The test stimulus ST was movable horizontally and its location was slightly varied from time to time to avoid the subject's memorizing the test stimulus arrangement of $\mathrm{N}_{1}$ and $\mathrm{N}_{2}$.

To vary the luminance level of the test stimulus as well as the adapting field, neutral density filters NF were placed in front of the subject's right eye. Eight different levels were investigated and they were $0.15,0.3,0.75,1.5,3,7.5,15$ and $30 \mathrm{~cd} / \mathrm{m}^{2}$, respectively, when measured over the test field and the adapting field. Three different ratios of $N_{1}$ and $\mathrm{N}_{2}$ were employed as the background condition and they were $\mathrm{N}_{1}-25 \%, \mathrm{~N}_{1}-50 \%$, and $\mathrm{N}_{1}-75 \%$, respectively. These correspond obviously to $\mathrm{N}_{2}-75 \%$, $\mathrm{N}_{2}-50 \%$, and $\mathrm{N}_{2}-25 \%$, respectively.

The spectral reflectance of the color chips employed as the target and the background noise $N_{1}$ and $\mathrm{N}_{2}$ is shown in Fig. 2 and are specifiable as 9.5Y5.6/7.1, 6.2R6.0/8.0, and 4.4G5.8/8.0, respectively in the Munsell notation.

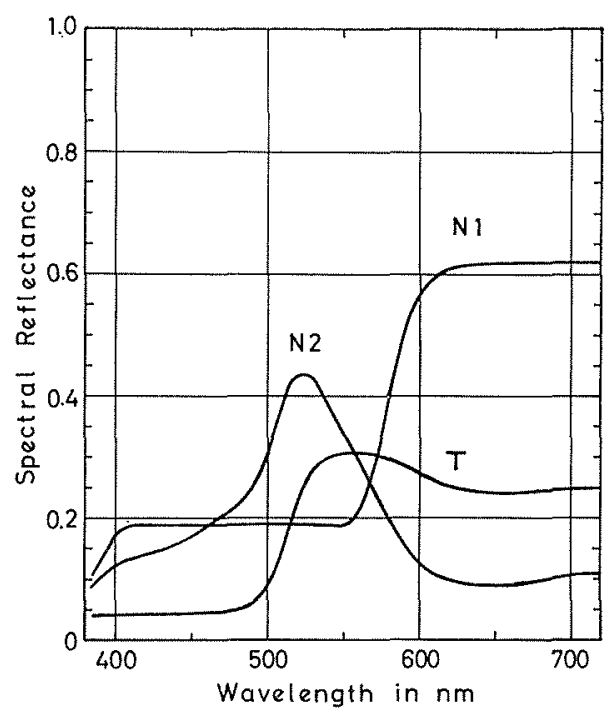

Fig. 2 Spectral reflectance curves of the target $\mathrm{T}$ and the background noises, $\mathrm{N}_{1}$ and $\mathrm{N}_{2}$

The experimental procedure was as follows. The subject was dark adapted for about ten to twenty minutes depending on the luminance level to be investigated. He then observed the adapting field and when ready he pressed the starting button to expose the test stimulus. He maintained his fixation during the exposure and searched for the test target. Immediately after the exposure he verbally reported the location of the target such as "upper right at a far distance." He could respond negatively, "I could not see." The experimenter recorded the subject's response and changed the target location on the test stimulus board and another exposure followed. Such exposure was repeated until a closed boundary of the functional visual field was obtained for a particular luminance level.

The neutral density filter was changed to provide another luminance level and the similar experiment was conducted, and so on. Only one male, MI was employed as the subject in the present report. He had a normal color vision and wore a glass to gain the visual acuity of 1.2 .

\section{Results and discussion}

Two examples of the functional visual field for the luminance $0.15 \mathrm{~cd} / \mathrm{m}^{2}$ (a) and $30 \mathrm{~cd} / \mathrm{m}^{2}$ (b) are shown in Fig. 3. Each unit along the abscissa and the ordinate gives $2^{\circ}$ arc of visual angle. The cross at the center shows the fixation point. Circles represent locations where the target was correctly detected while $x$ 's represent locations where the target was not detected correctly or at all. The boundaries between the circles and the x's should give the functional visual field limit and they are shown by solid lines. Because of a limited size of each color chip to $2^{\circ} \times 2^{\circ}$, some irregular shape of

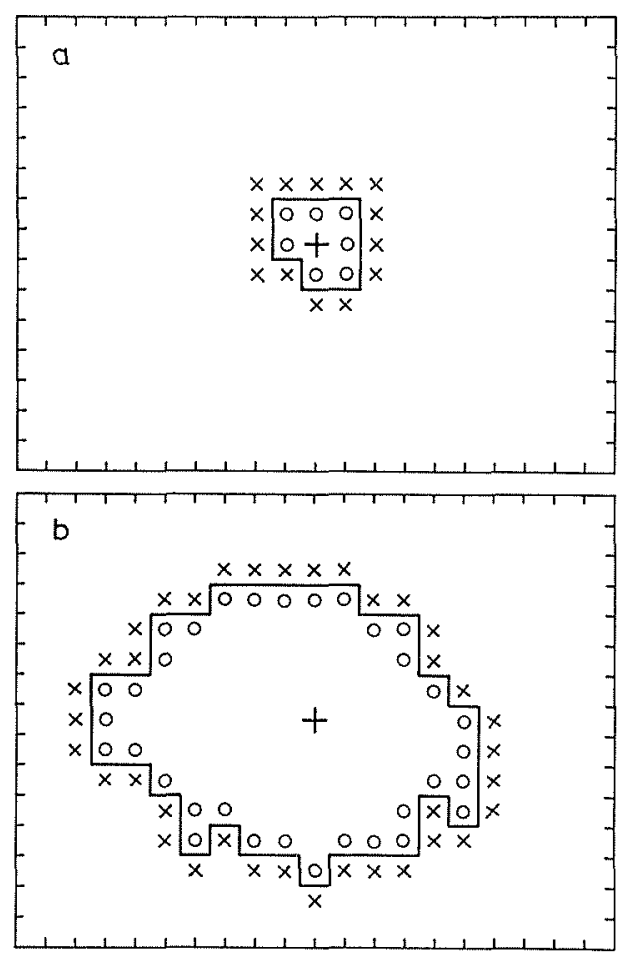

Fig. 3 Two examples of the functional visual field for luminance 0.15 $\mathrm{cd} / \mathrm{m}^{2}(a)$ and $30 \mathrm{~cd} / \mathrm{m}^{2}(\mathrm{~b})$. Each unit along the abscissa and the ordinate corresponds to $2^{\circ}$ arc of visual angle. 
the boundary was inevitable.

It is quite clear from Fig. 3 that the functional visual field size greatly depends upon the luminance level of the test stimulus and it shrinks as the luminance becomes low. To compare field sizes of various experimental conditions, each field was transformed into an equivalent circle with the same area and its diameter was obtained. Fig. 4 shows how the diameter varies as a function of the luminance. Each point was obtained by averaging three functional visual fields such as shown by Fig. 3. Three curves correspond to three different ratios of background noise; triangles: $\mathrm{N}_{1}-25 \%$, circles: $\mathrm{N}_{1}-50 \%$, and squares: $\mathrm{N}_{1}-75 \%$.

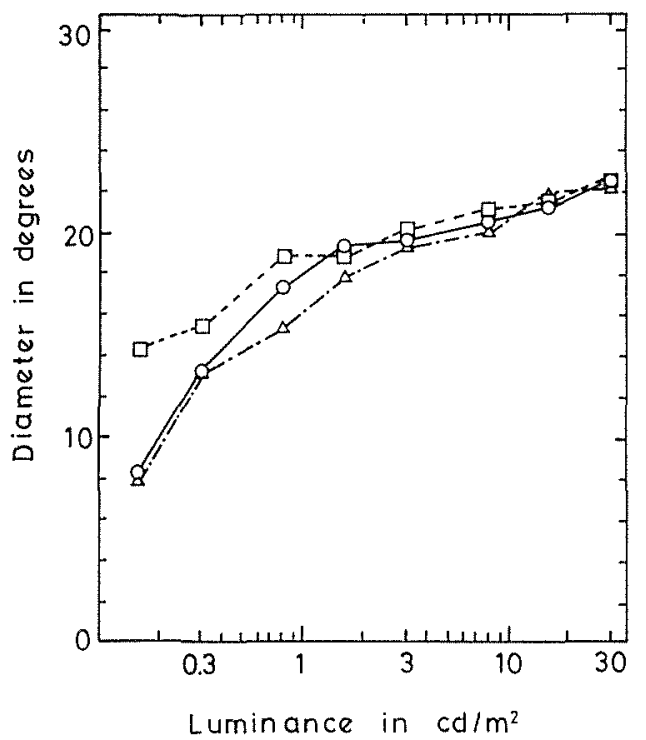

Fig. 4 Change of the functional visual field diameter as a function of the stimulus for three different $\mathrm{N}_{1}-\mathrm{N}_{2}$ ratios. Triangles: $\mathrm{N}_{1}-$ $25 \%$, circles: $\mathrm{N}_{1}-50 \%$, and squares: $\mathrm{N}_{1}-75 \%$.

The influence of the luminance level upon the functional visual field is quite evident. The functional visual field becomes smaller as the luminance level becomes lower and the diameter even becomes as small as $8^{\circ}$ arc of visual angle for conditions $\mathrm{N}_{1}-25 \%$ and $50 \%$ when the luminance was 0.15 $\mathrm{cd} / \mathrm{m}^{2}$. This is remarkably small in view of a large color difference between the target and both background colors that exists at a high luminance level. We notice a slight difference in $d-L$ curves of Fig. 4 when $\mathrm{N}_{1}-\mathrm{N}_{2}$ ratio changes. The curve of $\mathrm{N}_{1}-75 \%$ denoted by squares shows less deterioration when the luminance is reduced, compared to two other curves. The reason for this is not quite obvious. Munsell values of the target and the background noises were chosen about equal to eliminate cue for detection by the brightness difference. Such equality is no longer valid at the peripheral retina as suggested by the sensitivity increase in the blue region ${ }^{6)}$. The equality is subjected to a further alternation with the intrusion of rods at luminance extremely lowered. The change of relative brightness among three colors due to these new situations might be the cause for the difference observed among the $d-L$ curves.

It is hard to specify clearly a critical luminance below which the functional visual field abruptly decreases, but probably the curves of $\mathrm{N}_{1}-25 \%$ and $50 \%$ begin to drop rapidly at about $1.5 \mathrm{~cd} / \mathrm{m}^{2}$ and the curve of $\mathrm{N}_{1}-75 \%$ at $0.75 \mathrm{~cd} / \mathrm{m}^{2}$.

The task in which the subject was engaged in the present experiment is essentially the color discrimination between the target and the background noises. Thus the existence of the limited size in the functional visual field can readily be understood from the retinal property that the wavelength discrimination deteriorates more as its location aparts further away from the fovea ${ }^{(i)-8)}$.

When the luminance is lowered the wavelength discrimination becomes poor at any place of the retina including the fove ${ }^{(6) 8)-12}$. In particular Brown, who measured the MacAdam's ellipse at various luminance levels for several colors in the chromaticity diagram, showed that below about one foot-lambert or $3.4 \mathrm{~cd} / \mathrm{m}^{2}$ the ellipse became larger, slowly at first, and then more rapidly beyond about 0.5 foot-lambert. Our critical luminance for the field contraction is very close to this luminance value. It seems that the deterioration of the wavelength discrimination at a lowered luminance is inherent to the cone system as the phenomenon was observed at the fovea as experimented by all the above mentioned authors. But the deterioration is further emphasized, at the peripheral retina, by the rod intrusion when the luminance is lowered. This was clearly shown by the experiment in which the wavelength discrimination was determined at two temporal phases, one at the cone plateau and the other at the fully dark adapted state of the dark adaptation curve ${ }^{13)}$. The discrimination at $7.5^{\circ}$ off the fovea became very poor at the latter phase when the retinal illuminance was lowered to $3 \mathrm{td}$. The rod intrusion caused the deterioration. The lowest Iuminance level $0.15 \mathrm{~cd} / \mathrm{m}^{2}$ that we employed in the present experiment does not provide the complete scotopic vision, but it surely does the mesopic vision on which the rods become active. The contraction of the functional visual field shown in Fig. 4 was certainly caused, at least in part, by the intrusion of rods.

We are not claiming here that the luminance beyond the critical luminance, namely about $1.5 \mathrm{~cd} / \mathrm{m}^{2}$ is enough to assure a normal functional visual field. We only meant that the functional visual field was influenced by the luminance level and it reduced rather rapidly when the luminance was decreased below $1.5 \mathrm{~cd} / \mathrm{m}^{2}$. In application, however, it is very important to establish the critical luminance level below which the field size becomes too small to function in a normal manner in detecting a target out of colored background and a further experiment is needed where several subjects are investigated and other color combinations of the target and the background are employed. 


\section{References}

(1) N. H. Mackworth: "Visual noise causes tunnel vision," Psychonomic Science 3 (1965) 67 68.

(2) J.D. Chaikin, H. H. Corbin and J. Volkmann: "Mapping a field of short-time visual search," Science 138 (1962) $1327 \sim 1328$.

(3) F. L. Engel: "Visual conspicuity, directed attention and retinal locus," Vision Res. 11 (1971) 563 575.

(4) M. Ikeda and H. Uchikawa: "Functional visual fields for detecting a colored target," Acta Chromatica 3 (1979) $141 \sim 146$.

(5) M. Ikeda and T. Takeuchi: "Influence of foveal load on the functional visual field" Percept. Psychophys. 18 (1975) $255 \sim 260$.

(6) R. A. Weale: "Spectral sensitivity and wave-length discrimination of the peripheral retina," J. Physiol. 119 (1953) $170 \sim 196$,

(7) J.D. Moreland: Peripheral color vision, Handbook of
Sensory Physiology, VII/4 Visual Psychophysics, 517-536 Jameson \& Hurvich ed., Springer-Verlag, Berlin (1972).

(8) R. A. Weale: "Hue-discrimination in para-central parts of the human retina measured at different luminance levels," J. Physiol. 113 (1951) 115 122.

(9) M. Gilbert: "Colour perception in parafoveal vision," Proc. Phys. Soc. B63 (1950) 83 89.

(10) W. R. Brown: "The influence of luminance level on visual sensitivity to color differences," J. Opt. Soc. Am. 41. (1951) $684 \sim 688$.

(11) L. C. Thomson and P. W. Trezona: "The variations of hue discrimination with change of luminance level," $\mathrm{J}$. Physiol. 114 (1951) 98 106.

(12) K. J. McCree: "Small-field tritanopia and the effects of voluntary fixation," Optica Acta 7 (1960) 317 323.

(13) U. Stabell and B. Stabell: "Wavelength discrimination of peripheral cones and its change with rod intrusion," Vision Res. 17 (1977) 423 426.

Received 22 Oct. 1980; Revision Received 19 Jan. 1981 